\title{
Effect and key factors of byproducts valorization: The case of dairy industry
}

\author{
A. Banaszewska, ${ }^{*}{ }^{1}$ F. Cruijssen, ${ }^{*}$ G. D. H. Claassen, ${ }^{*}$ and J. G. A. J. van der Vorst ${ }^{\star}$ \\ "Logistics, Decision and Information Sciences, Wageningen University and Research Centre, Hollandseweg 1, 6706 KN Wageningen, \\ the Netherlands \\ †FrieslandCampina, Stationsplein 4, 3818 LE Amersfoort, the Netherlands
}

\begin{abstract}
Production of many consumer products results in byproducts that contain a considerably large part of nutrients originating from input materials. High production volumes, environmental impact, and nutritional content of byproducts make them an important subject for careful valorization. Valorization allows us to explore the possibility of reusing nutrients in the production of main products, and thus highlights the potential gains that can be achieved. The main aim of this study was to evaluate the added value of cheese whey valorization, and to determine the effect of integral valorization of main products and byproducts on the profit of a dairy producer. Several scenarios and cases were implemented and analyzed using a decision support tool, the integral dairy valorization model. Data originated from the international dairy processor FrieslandCampina (Amersfoort, the Netherlands). The outcomes of scenarios were analyzed with regard to profit and shifts in the production of nonwhey end products, and were validated by company experts. Modeling results showed that the valorization of byproducts is very profitable (24.3\% more profit). Furthermore, additional profit can be achieved when 2 valorization processes (main products and byproducts) are integrated. This effect is, however, considerably affected by current capacity and market demand limitations. Significant benefits can be created if demand of whey-based products is increased by $25 \%$.
\end{abstract}

Key words: byproducts valorization, whey, profit maximization, production

\section{INTRODUCTION}

As the global population is growing, significantly more food is needed to feed the world. This can be achieved, in part, by increasing farm production levels. It might, however, be more effective to reduce food

Received July 24, 2013.

Accepted December 2, 2013.

${ }^{1}$ Corresponding author: agata.banaszewska@wur.nl waste in supply chains. Recent studies of the Food and Agriculture Organization of the United Nations (Gustavsson et al., 2011) estimate that globally 40 to $50 \%$ of fruits and vegetables, $20 \%$ of meat and dairy, and $30 \%$ of fish are wasted. This creates an enormous waste of resources and calls for research to reduce the problem.

Food waste is food that is discarded or lost uneaten. Food wastes take place at the production, postharvest, and processing stages in the food supply chain (Parfitt et al., 2010). In most European legislations, production residues are defined as wastes; however, scientists who investigate the potential of reusing food wastes define them as food byproducts (Galanakis, 2012). In this paper, we investigate valorization of byproducts in the milk processing industry. Valorization is defined as the optimal postprocessing of byproducts incorporated in the production of main milk products. Different ways of valorizing byproducts have been investigated in various industries; for example, citrus, fish, meat, cereals, roots and tubers, oil crops, and dairy (see Table 1 for references). Most of these studies are focused on biotechnological developments and investigate the possibility of extracting various nutrients from byproducts and the possibility of using (parts of) the byproducts in the production of end products. The main objective is usually to decrease the environmental impact and reduce costs related to byproduct processing technology (Galanakis, 2012; Mollea et al., 2013). Although the biology and technology aspects are well studied, to the best of our knowledge, no studies have evaluated the overall economic effect of postprocessing of byproducts on a food processor (see Table 1). The maximization of processor profitability, especially if processors reuse their own byproducts in the production of their end products, is not a key aspect of these studies. Furthermore, the effect of biotechnological developments in extracting and reusing nutrients contained in byproducts on the valorization of main products was not investigated.

In this paper, we focused on the dairy industry and analyzed the effect of byproducts valorization on the overall valorization of raw milk. We investigated how different levels of valorization of byproducts affect production planning decisions related to main end products 
Table 1. Literature on the valorization of byproducts (adapted from Galanakis, 2012)

\begin{tabular}{|c|c|c|}
\hline Valorized byproduct & Reference & Objective of valorization \\
\hline \multirow[t]{2}{*}{$\begin{array}{l}\text { Citruses (e.g., orange peel as a } \\
\text { byproduct of orange) }\end{array}$} & Chedea et al. (2010) & $\begin{array}{l}\text { Characterization of carotenoid pattern in two varieties of orange waste (Valencia and Navel) using } \\
\text { different analytical methods }\end{array}$ \\
\hline & Farhat et al. (2011) & $\begin{array}{l}\text { Optimization of operating conditions for the optimal extraction time of essential oil from orange } \\
\text { peel }\end{array}$ \\
\hline Fish (e.g., fish leftovers) & Gehring et al. (2011) & $\begin{array}{l}\text { Review of isoelectric solubilization/precipitation (ISP) developments to recover proteins and lipids } \\
\text { from fish byproducts }\end{array}$ \\
\hline \multirow{3}{*}{$\begin{array}{l}\text { Meat (e.g., bovine blood as a } \\
\text { byproduct of bovine production) } \\
\text { Cereals (e.g., bran and straw as a } \\
\text { byproducts of wheat) }\end{array}$} & Darine et al. (2010) & $\begin{array}{l}\text { Investigation of protein recovery and physicochemical properties of meat protein concentrates from } \\
\text { beef lungs }\end{array}$ \\
\hline & Sun and Tomkinson (2002) & $\begin{array}{l}\text { Investigation of the extractability of the wheat straw hemicelluloses using extraction method with } \\
\text { and without application of ultrasonic irradiation }\end{array}$ \\
\hline & Hollmann and Lindhauer (2005) & $\begin{array}{l}\text { Development of an economically viable procedure for the isolation of the glucuronoarabinoxylans } \\
\text { from wheat bran }\end{array}$ \\
\hline \multirow{2}{*}{$\begin{array}{l}\text { Oil crops (e.g., olive pomace and } \\
\text { wastewater as a byproduct of olive } \\
\text { production) }\end{array}$} & Yang et al. (2010) & $\begin{array}{l}\text { Investigation of a catalytic decomposition and effects of different solvents on the purity and yield of } \\
\text { recover phytosterols from the waste residue of soybean oil deodorizer distillate }\end{array}$ \\
\hline & Galanakis (2011) & $\begin{array}{l}\text { Review of the compositional and structural characterization of olive dietary fiber, the modifications } \\
\text { during olive fruit ripening and processing, the recovery and potential applications of dietary fiber } \\
\text { from olive byproducts }\end{array}$ \\
\hline \multirow[t]{4}{*}{$\begin{array}{l}\text { Dairy (e.g., whey as byproduct of } \\
\text { cheese production) }\end{array}$} & Koutinas et al. (2009) & $\begin{array}{l}\text { Development of an integrated technology for starter culture production from whey for use in cheese } \\
\text { ripening }\end{array}$ \\
\hline & Guimarães et al. (2010) & Review of fermentation of lactose to ethanol with the focus on wild lactose-fermenting yeasts \\
\hline & Patel and Murthy (2011) & $\begin{array}{l}\text { Investigation of the recovery of lactose from partially deproteinated whey by the use of an anti- } \\
\text { solvent }\end{array}$ \\
\hline & Prazeres et al. (2012) & $\begin{array}{l}\text { Review of four main cheese whey management practices: biological treatments without valorization, } \\
\text { biological treatments with valorization, physicochemical treatments and direct land application }\end{array}$ \\
\hline
\end{tabular}


and the resulting profit of a processor. To evaluate the effect of byproducts valorization, we used the largest byproduct of the dairy industry - whey (Koutinas et al., 2009) - as a case study. The dairy industry is focused on maximizing the value of all nutrients contained in the main raw material; that is, raw milk. Byproducts contain various valuable nutrients; thus, their reuse in the production process allows efficient exploitation of all nutrients available in raw milk. Constant developments in science and technology enable the production of sophisticated dairy products (FAO, 2009). However, this implies that the processing of dairy products becomes a complex network of interrelated production processes. Often, production of a certain dairy product results in an additional residual dairy flow - a byproduct. For instance, production of cheese results in additional production of whey and cream; production of butter results in additional buttermilk; and production of butter oil results in additional cream serum (see Figure 1).

We chose whey byproduct as the subject of this study for 3 main reasons:

(1) The high nutritional content of whey. Whey is a byproduct of caseinate and cheese manufacturing, although cheese production is its major source (FAO, 2009). During the cheese production process, the fat and casein proteins in raw milk are aggregated into a curd, and the soluble whey proteins, lactose, and minerals are contained in whey (González-Martínez et al., 2002). As much as 55\% of the total milk nutrients (lactose, hydrosoluble minerals, vitamins, and $20 \%$ of milk proteins) are retained in whey (González-Martínez et al., 2002; Panesar et al., 2007; Smithers, 2008).

(2) The high environmental impact. The lactose part of whey, which amounts to $75 \%$ of the total whey solids, qualifies whey as a highly polluting product (Marwaha and Kennedy, 1988; González-Martínez et al., 2002; Smithers, 2008). The disposal of whey causes major environmental problems, because it affects the physical and chemical structure of soil (Marwaha and Kennedy, 1988; Gonzalez-Siso, 1996; Koutinas et al., 2009). In fact, whey is considered one of the most polluting food byproduct streams (Gonzalez-Siso, 1996). However, given developments in chemistry and technology, the protein and peptide part of whey protein make it a potential raw material for the production of various high-value products in the agri-food, biotechnology, and pharmaceutical industries (Panesar et al., 2007; Smithers, 2008; Cuartas-Uribe et al., 2009; Koutinas et al., 2009). The lactose part of whey found its application in the production of main dairy products. Lactose is often used to standardize protein levels in milk end products (see Figure 1).

(3) The high production volume of whey. A schematic representation of the increase in the value of whey products over the last $60 \mathrm{yr}$ is presented in Figure 2. It is therefore known which gains could be obtained from transforming whey byproducts into whey-based end products. The interesting question, however, is whether the incorporation of whey valorization affects profit and production of residual nonwhey products. For instance, does the production of whey-based products affect produced volumes of cheese? A decision to increase cheese production might be taken in a situation when profit margins of whey end products are high enough. Furthermore, Russ and Meyer-Pittroff (2004) estimated a specific waste index that is a ratio of the mass accumulated in waste to the mass of an end product. The authors showed that, depending on the type of cheese, the cheese whey index lies between 4 and 11.3, which is high compared with waste indexes in other industries (i.e., between 0.001 and 0.87 ). Moreover, over onethird $(35 \%)$ of worldwide supplied milk is processed into cheese (FAO, 2009). The outlook for production in 2025 indicates an increase of cheese production of $24 \%$ in the European Union (Figure 3) and 32\% worldwide (FAPRI, 2012). Therefore, whey production will also increase.

The high production of whey, its high environmental impact, and its high nutritional content indicate that this byproduct is an important byproduct for which careful valorization is important. The aim of this study was to evaluate the effect of whey valorization on the overall valorization of raw milk. Two valorization techniques were employed and compared: a traditional milk valorization and subsequent separate whey valorization (as now applied in practice to some extent), and an integral valorization (integrated nonwhey and whey valorization). The integral valorization is a new approach to valorize milk and whey products in practice. To attain the research aims, we posed 4 questions. First, what is the added value of the whey valorization (i.e., gain in profit)? Second, what is the overall added value of the integral valorization? Third, which input parameters drive the effect of the integral valorization (e.g., prices, demand, capacities)? Fourth, given the highly interrelated production of dairy products, does the integration of the valorization of milk and whey products affect the choice of milk end products to be produced? 


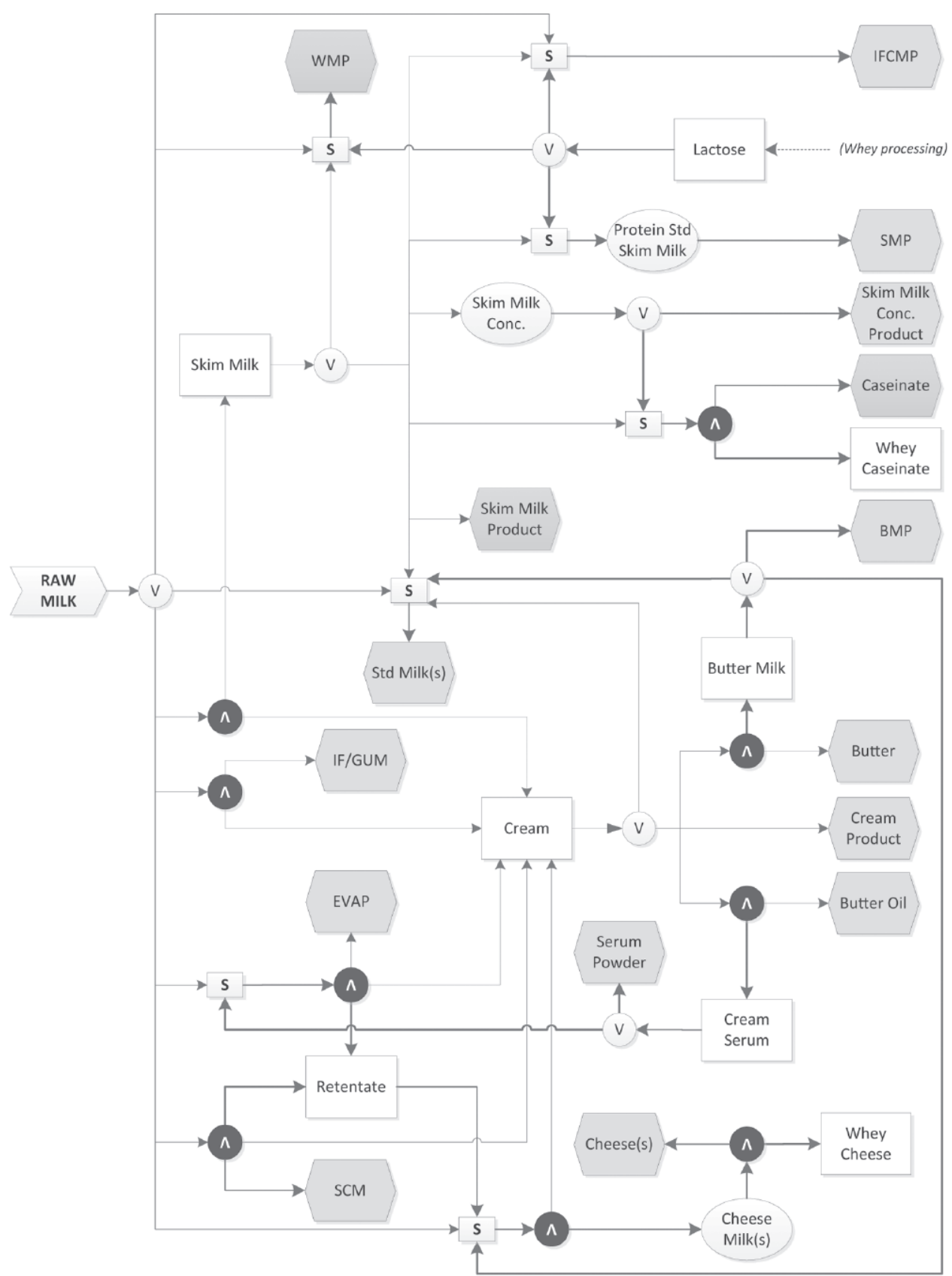

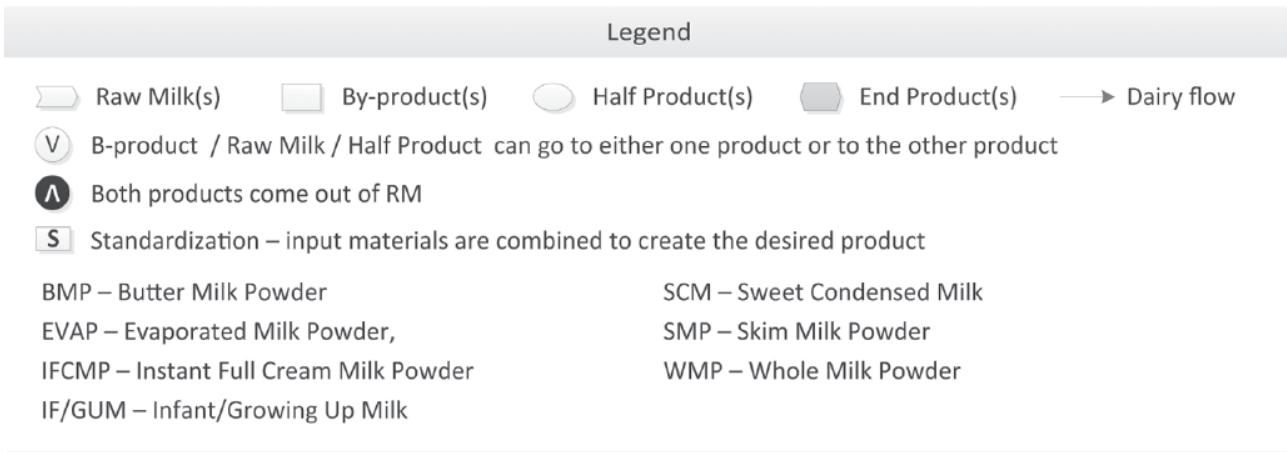

Figure 1. Schematic representation of dairy flows (adapted from Banaszewska et al., 2013). 


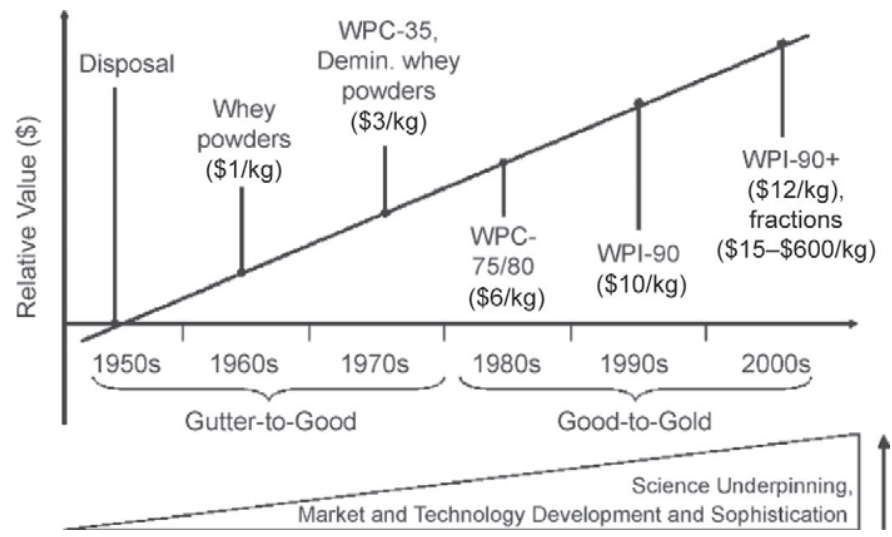

Figure 2. Schematic representation of the relative change in the value of whey products. WPC $=$ whey protein concentrates; WPI = whey protein isolates. Reprinted from International Dairy Journal, Vol. 18/No. 7, Geoffrey W. Smithers, "Whey and whey proteinsFrom 'gutter-to-gold'", 695-704, 2008, with permission from Elsevier.

\section{MATERIALS AND METHODS}

To evaluate the effect of whey valorization on the overall valorization, we used the integral dairy valorization model (IDVM), an amended version of the dairy valorization model (DVM) developed by Banaszewska et al. (2013). The data used for scenario analyses were collected at FrieslandCampina (FC; Amersfoort, the Netherlands), one of the largest dairy companies in the world.

\section{DVM and IDVM}

The DVM is a linear programming model designed to create mid-term valorization plans. The supplied raw milk is allocated to a wide range of dairy products. The products are divided into 4 categories: (1) raw milks, (2) byproducts (products additionally obtained while producing main products and decomposing raw milks),
(3) half products (products produced to be used in the production of end products; an intermediate step in the production that is necessary to obtain final end products), and (4) end products (products that are not reused in the production of other products, but are only sold on the market). The assignment of products to the enumerated categories is not always straightforward. Some byproducts such as skim milk and cream can also be perceived as half-products, as they are often intentionally produced to obtain input for the production of main end products. For instance, decomposition of milk is carried out to obtain skim milk and cream. These are usually high-value byproducts. However, in this study, we focused on the valorization of low-value byproducts such as whey.

The DVM maximizes the profit of a producer while accounting for all important constraints. The objective function is the maximization of the difference between the revenue from sales and various costs (production, transport, and purchase). The following constraints are incorporated in the model:

(a) Capacities - ensures that amount of capacity of a certain resource used does not exceed the available capacity;

(b) Supply of raw milk - ensures that all milk supplied to a producer is either processed into end products or sold directly on the market;

(c) Total sales - ensures that total sales of a product do not exceed maximum allowed sales volumes (often limited by contracts or market capacity);

(d) Sales and purchase per tranche - ensures that amount of a product sold (purchased) for a certain price does not exceed the maximum sales (purchase) volume assigned to a tranche. A tranche indicates the maximum sales (purchase) volume of a product that can be sold (purchased) for a specific tranche-dependent price;

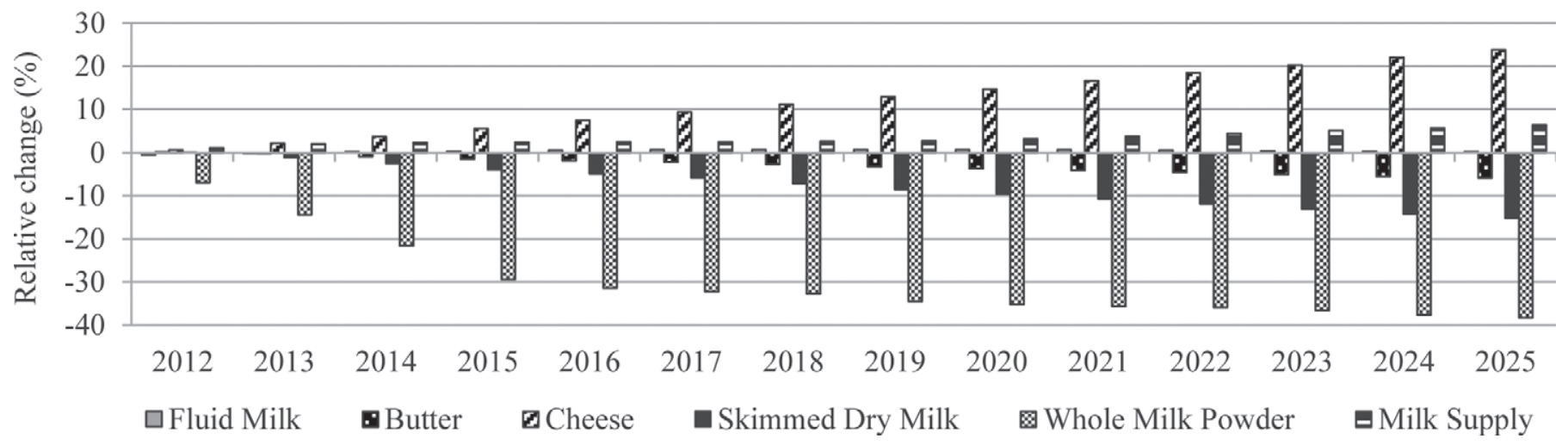

Figure 3. Relative percentage changes in the expected dairy production and milk supply in the European Union. Year 2011 used as a base year (FAPRI, 2012). 
(e) Recipes - maintains the correct relation between the volume of a product produced, the volume of an input material required, and the volume of a byproduct obtained;

(f) Composition balance - ensures that total volume of DM, fat, or protein contained in input materials used for a production of a certain product equals the volume of that component present in production's outputs (desired product and byproducts);

(g) Inflow volumes - ensures that the volume of a certain material used for a production at a certain location equals the sum of the volume of that material delivered from other locations and the volume purchased on the market;

(h) Outflow volumes - ensures that the volume of a certain product produced at a certain location equals the sum of the volume of that product transported to other locations and the volume sold on the market.

Banaszewska et al. (2013) showed that the developed DVM represents the dairy system well when whey processing is not included. To incorporate all whey streams and accomplish the integral valorization, the original DVM was slightly amended, which resulted in the IDVM. The main implications relate to the use of production resources by half products and end products, and to the lactose component. The investigation of whey production processes indicated the possibility of producing a certain product at a certain location with multiple production resources. In the DVM, it was assumed that each product uses one production resource at a certain location. Consequently, in the IDVM, in the constraints related to capacities, recipes, outflow volumes, and in the objective function, the variable $\operatorname{Xprod}_{\left(t, d, d^{\prime}, i, l\right)}$, representing the volume of a product $d$ obtained from the production of a product $d^{\prime}$ with a recipe $i$ at a location $l$ in a time period $t$, was replaced with $\sum_{r} \operatorname{Xprod}_{\left(t, d, d^{\prime}, i, r, l\right)}$ for $d=d^{\prime}$ and $d \in E \cup H$, where $r$ indicates a production resource, $E$ a set of end products, and $H$ a set of half products. In constraints related to composition balance, the following changes were made:

$$
\sum_{d \in D \backslash M} Y_{(t, d)} \cdot \operatorname{Xprod}_{\left(t, d, d^{\prime}, i, l\right)}
$$

was replaced with

$$
\sum_{b} Y_{(t, b)} \cdot \operatorname{Xprod}_{\left(t, b, d^{\prime}, i, l\right)}+\sum_{d \in E \cup H, d=d^{\prime}} Y_{(t, d)} \cdot \sum_{r} \operatorname{Xprod}_{\left(t, d, d^{\prime}, i, r, l\right)}
$$

where $Y=$ the fat, protein, or DM component, and $b=$ a byproduct. The first term of the equation indicates the volume of a component present in byproducts obtained while producing the main product $d^{\prime}$. The second term indicates the volume of a component present in that main product. Furthermore, because whey products are rich in lactose and, in the DVM, only protein, fat, and DM components were considered, an additional parameter representing lactose content in a product $\left[L a c_{(t, d)}\right]$ was added to the IDVM. Moreover, a composition balance constraint related to lactose was also added:

$$
\begin{aligned}
& \sum_{d \in D \backslash E} \operatorname{Lac}_{(t, d)} \cdot \operatorname{Xuse}_{\left(t, d, d^{\prime}, i, l\right)}=\sum_{b} \operatorname{Lac}_{(t, b)} \cdot \operatorname{Xprod}_{\left(t, b, d^{\prime}, i, l\right)} \\
& +\sum_{d \in E \cup H, d=d^{\prime}} \operatorname{Lac}_{(t, d)} \cdot \sum_{r} \operatorname{Xprod}_{\left(t, d, d^{\prime}, i, r, l\right)}+\operatorname{Wlac}_{\left(t, d^{\prime}, i, l^{\prime}\right)}
\end{aligned}
$$

for $d^{\prime} \in D \backslash B$ and $\forall d^{\prime} i, l^{\prime}, t$.

\section{Data Collection and Results Validation}

Input data necessary for the study (i.e., recipes, composition, whey markets, production costs, production rates, new capacities, and interrelations between products) were collected at FC. Because data were coming from multiple sources at the company, they were verified during multiple individual and group interviews before being entered into the model. Interviews were held with relevant FC employees, including dairy supply chain manager, technologists, financial employees, and the whey valorization planner. Additionally, early outputs of the model and findings were discussed in multiple workshops with company experts to verify whether obtained results were realistic and whether all data were correct.

\section{Evaluation Approach}

To evaluate the effect of whey valorization and the integral valorization on the company performance, the analysis was performed in 2 steps. In the first step (the base scenario analysis), the IDVM was run with the input data representing the production, supply, and market situation in 2011. In the second step (the sensitivity analysis), multiple scenarios were defined and run to confirm and refine the conclusions obtained in the first step of analysis. In every scenario, values of certain input parameters were altered. To conduct one full scenario analysis, the model had to be run for 3 different cases (see Figure 4 for a schematic overview of the analysis approach). 
In the first case, only the valorization of nonwhey dairy products was allowed, called the nonwhey valorization (NW) case. These are the products included in the study of Banaszewska et al. (2013). In the second case, called the stepwise valorization $(\mathbf{S W})$ case, the production levels of nonwhey-based products were set to the optimal production levels as found in the first case, and additionally the valorization of whey products was allowed. The SW valorization represents the situation when the decision on the production of nonwhey products does not depend on the possibilities of further processing of whey byproducts. In the third case, called the integral valorization (Int) case, all products were valorized at the same time. To summarize, the full analysis of each scenario required 3 model runs, each run relating to a specific case: NW, SW, or Int.

The evaluation of the effect of the Int valorization was based on 2 measures: profit and end production volumes. Both measures were expressed as differences between Int and SW cases. The comparison of the profit of Int and SW cases indicates the gain that companies achieve by integrating whey valorization into the first step of the milk valorization process. The comparison of production levels of Int and SW cases indicates the effect of whey valorization on the production of nonwhey end products.

\section{RESULTS AND DISCUSSION}

The effect of whey valorization and integral valorization were analyzed in detail and presented based on the case study of FC. The analysis of the base scenario for all 3 cases provided good insight into gains that the case company could currently achieve from the valorization of byproducts and from the integration of both valorization processes. To answer the third research question (i.e., to identify input parameters that drive the effect of the integral valorization), sensitivity analysis was conducted on the main constraints. Particular emphasis was placed on the analysis of the effect of integral valorization, because experts from practice

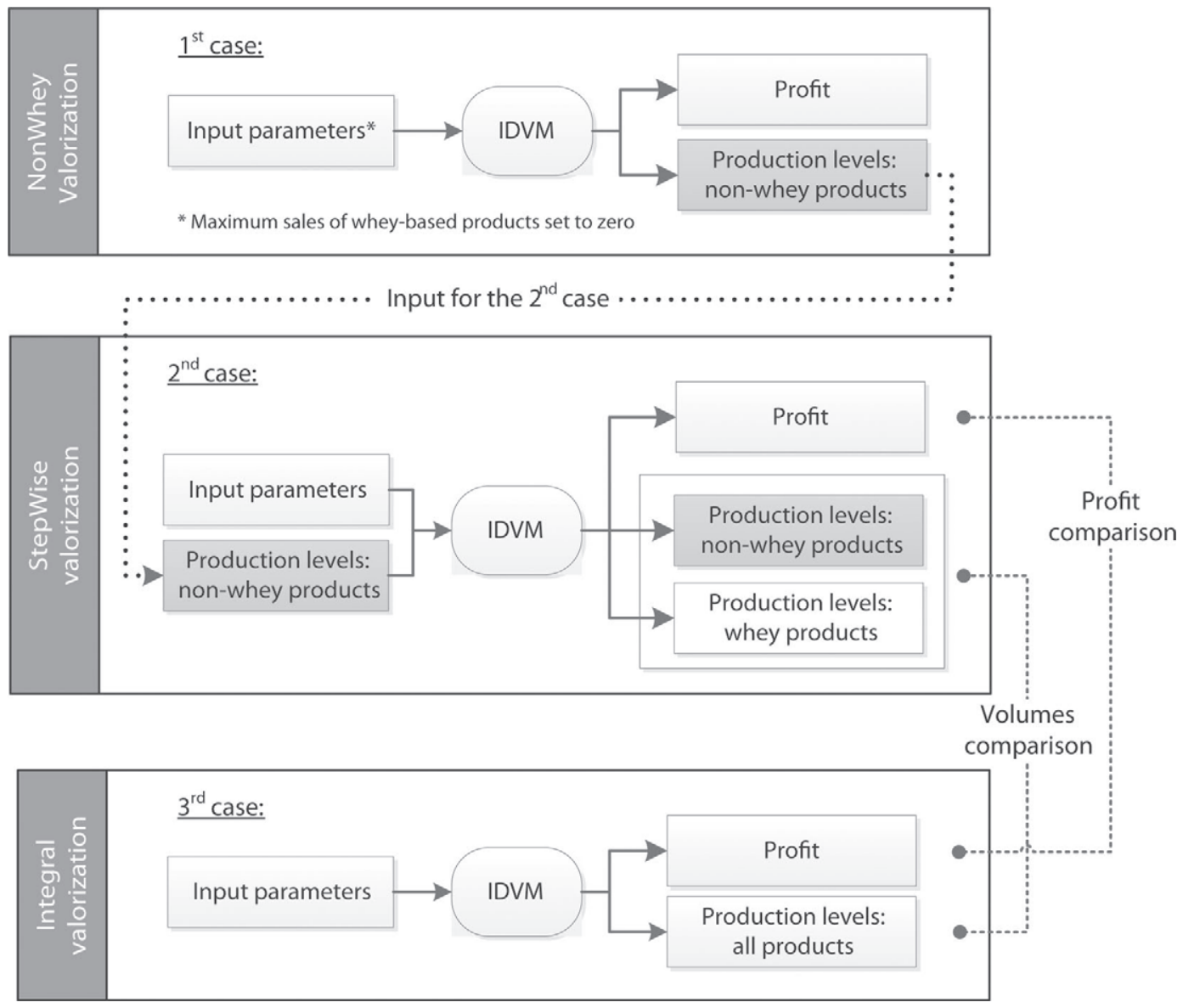

Figure 4. Analysis approach used to evaluate the effect of whey valorization on the overall valorization. IDVM = integral dairy valorization model. 
expect high gains from the integration of both valorization processes.

To conduct analyses, several scenarios were defined and built into the IDVM. All scenario runs were conducted with the use of the optimization software package AIMMS 3.12 (Paragon Decision Technology B.V., Haarlem, the Netherlands). The results of the analyses are presented below.

\section{Input Data of the Case Study}

The original product portfolio used by Banaszewska et al. (2013) to valorize raw milk was extended with whey products. The set of representative whey products was identified based on investigation of the whey product portfolio of FC. The list of whey-based end products included in analyses is provided in Table 2 . The flow diagram of all whey-based dairies is depicted in Figure 5. The original product IF/GUM included in the DVM was split into 2 end products in the IDVM: infant formula (IF) and growing-up milk (GUM). The inclusion of whey-based products in the IDVM allowed for the better representation of IF and GUM production recipes, which incorporate the use of 3 different whey-based products. More detailed representation of production processes revealed considerable differences between the recipes of those end products, and thus we decided to split IF/GUM into 2 products.
It is important to note that IF and GUM products use, as input, raw milk and whey-related inputs (Figure 5 ), and thus they can be treated as either nonwhey or whey end products, and can be valorized in either the NW or the SW case. We decided to treat those products as nonwhey products because, in practice, the decision on production levels of IF and GUM does not depend on the valorization of whey-based products. In reality, because of high profitability, IF and GUM products are always produced in the highest possible volumes. To allow the production of GUM and IF in the NW case (only), their recipes were adjusted; that is, we assumed that only raw milk was used as input, and production costs were increased by the production costs of wheybased inputs. Another assumption was also made on the source cost of lactose byproduct in NW cases. In these cases, lactose byproduct can be sourced only from the spot market for a high purchase price (mean of $€ 1,438 / \mathrm{t}$ ), whereas in reality (with current demand and production capacities), all lactose byproduct is sourced internally from the production of other products. To enable realistic decision making on the optimal production levels of nonwhey products using lactose as input (i.e., instant full cream milk powder/whole milk powder/skim milk powder, IFCMP/WMP/SMP), another purchase tranche of lactose byproduct was introduced in the NW cases only. The purchase price was equal to the internal cost price of lactose byprod-

Table 2. Whey-based end products included in the integral dairy valorization model

\begin{tabular}{ll}
\hline Full name of product & Abbreviation \\
\hline Protein-rich cheese whey fat powder type I & PRChWFP (I) \\
Demineralized whey powder 50 & DWP50_EP \\
Demineralized whey powder 90 & DWP90 \\
Delactosed permeate powder & DLP \\
Whey protein concentrate 30 & WPC30 \\
Galactooligosaccharides powder & GOS \\
Protein-rich cheese whey fat powder type II & PRChWFP (II) \\
Hiprotal30 & - \\
Hiprotal35 & - \\
Hiprotal35BL & - \\
Hiprotal45_EP & - \\
Hiprotal60MP & - \\
Hiprotal75BL & - \\
Hiprotal80BL & - \\
Protein-rich casein whey powder & PRCaWP \\
Protein-rich cheese whey powder & PRChWP_Prod \\
Permeate powder casein & PPCasein \\
Permeate powder cheese & PPCheese \\
Protein-rich cheese whey fat powder type III & PRChWFP (III) \\
Vivinal Alpha & - \\
Whey powder feed & - \\
Whey powder food & - \\
Whey protein concentrate 80 & WPC80 \\
\hline
\end{tabular}

${ }^{1}$ Hiprotal X = special types of whey protein concentrate products (from FrieslandCampina, Amersfoort, the Netherlands), where $\mathrm{X}$ indicates product-specific percentage of contained whey protein; BL indicates products rich in $\beta$-LG.

${ }^{2}$ Vivinal Alpha $=$ a whey protein concentrate product rich in $\alpha$-LA (FrieslandCampina). 


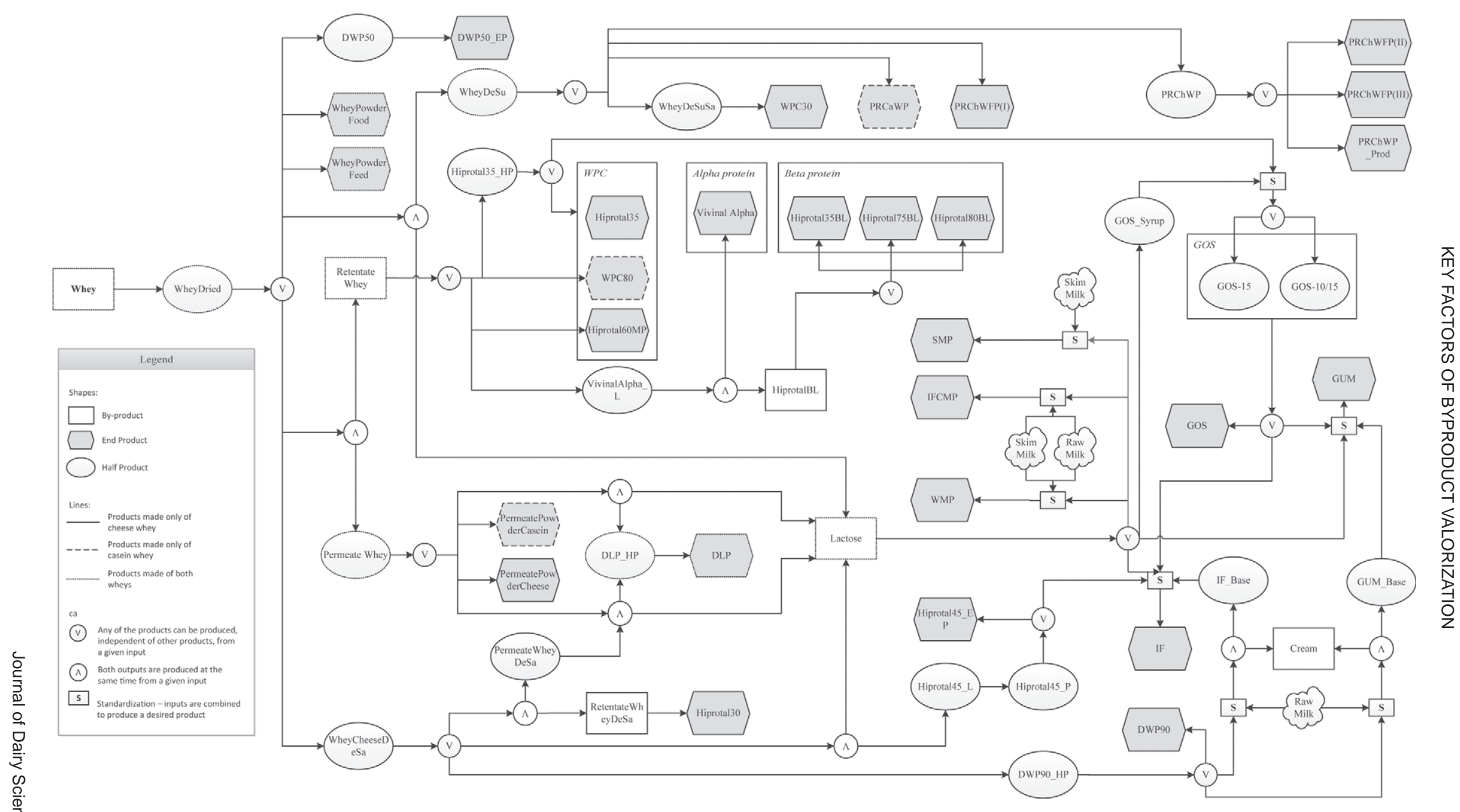

Figure 5. Flow diagram of all whey-based dairies. WheyDeSu $=$ desugared whey, WheyDeSuSa $=$ desugared desalted whey, WheyCheeseDeSa $=$ desalted cheese whey, PermeateWheyDeSa $=$ desalted whey permeate, RetentateWheyDeSa $=$ desalted whey retentate, $\mathrm{L}=$ liquid form of a product, $\mathrm{P}=$ powder form of a product, HP $=$ half product for production of a certain product. Other abbreviations are given in Figure 1 and Table 2. 


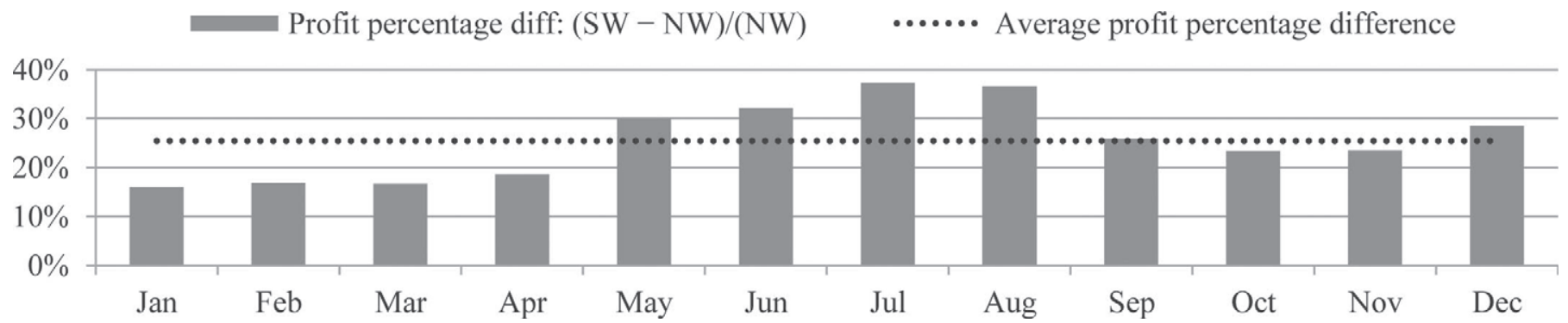

Figure 6. Percentage differences in profit between stepwise valorization (SW) and nonwhey valorization (NW) cases of the base scenario.

uct, and the maximum purchase volume was set to the optimal production level of lactose byproduct, as indicated in the Int case of the base scenario. Lactose necessary to produce IFCMP/SMP/WMP in the SW cases came from internal production. Even without the additional assumption on the purchase of lactose byproduct, no differences in the production volumes of IFCMP/WMP/SMP products between Int and SW cases were observed in the base scenario. Therefore, the effect of the integrated model is not affected. However, comparison of the SW and NW cases (i.e., the effect of the whey valorization) becomes more realistic, because costs in NW cases are much lower because of the lower sourcing cost of lactose byproduct.

\section{First Step Analysis: Base Scenario}

Three main outcomes of all valorization plans were analyzed: profit, produced volumes of end products, and market and capacity limitations. Because of data confidentiality, percentage differences in profit were analyzed instead of absolute differences. Before moving to the results of the integral analyses, we first assessed the effect of whey valorization; that is, the overall additional profit dairy companies can reach by explicitly valorizing the whey byproduct.

Differences in Profit. Profit percentage differences between the SW and NW cases of the base scenario are shown in Figure 6. On average, the percentage difference in profit amounted to $25.5 \%$ per month. The total profit from processing whey byproducts amounted to $24.3 \%$ of the profit obtained from producing milk-based products. This is a considerable gain for the company, but also a gain for the environment, because disposing of the whey byproduct becomes unprofitable.

Figure 7 depicts the percentage differences in profit when the integral valorization is applied; that is, the percentage differences between the Int and SW cases of the base scenario. On average, they amounted to $0.0089 \%$ per month. Only in April was the difference higher (i.e., around $0.095 \%$ ) because of the small difference in the sale prices of IFCMP and cheese in that month. From a profit perspective, we may conclude that the integral valorization has either a small effect or that in the current settings the dairy system was too restricted by various constraints, and thus there was no room for extra valorization.

Additionally, we analyzed whether patterns of profit (percentage) differences between SW and NW cases and between Int and SW cases follow the seasonality pattern of raw milk. We concluded that the similarities in these patterns were not strong enough to assume well-founded coherency. The analysis was based only on the 2011 data, and perhaps additional analysis of patterns from previous years would allow for a stronger conclusion.

Shifts in Production Planning. Differences in the produced volumes of end products between Int and SW cases of the base scenario are presented in Figure 8. As can be seen from Figure 8, in the integral valorization, a shift occurred from the production of natural cheese to the IFCMP/WMP products. This can be explained by the relation between the prices of those products. The sale price of natural cheese was, in all months but April, €501/t higher, on average, than the prices of IFCMP/WMP. In April, however, the price of natural cheese was $€ 10 / t$ lower. Consequently, in the Int case, profit obtained from $1 \mathrm{t}$ of raw milk used for the production of natural cheese was lower than the profit obtained from $1 \mathrm{t}$ of raw milk allocated to IFCMP/ WMP production. This situation occurred only in the Int case because in the SW valorization, the possibility of internally obtaining lactose byproduct (the input for IFCMP/WMP) was not apparent. Therefore, the decision to switch from the production of natural cheese to IFCMP/WMP was not made, because the high production costs (cost of inputs) of IFCMP/WMP negatively affect the profit margin. This switch was made in the Int valorization, because the possibility of obtaining lactose byproduct internally was apparent, and therefore each ton of raw milk allocated to IFCMP/WMP valorized better than the ton of raw milk allocated to natural cheese. Differences in the production of residual products visible in Figure 8 were linked to the switch 


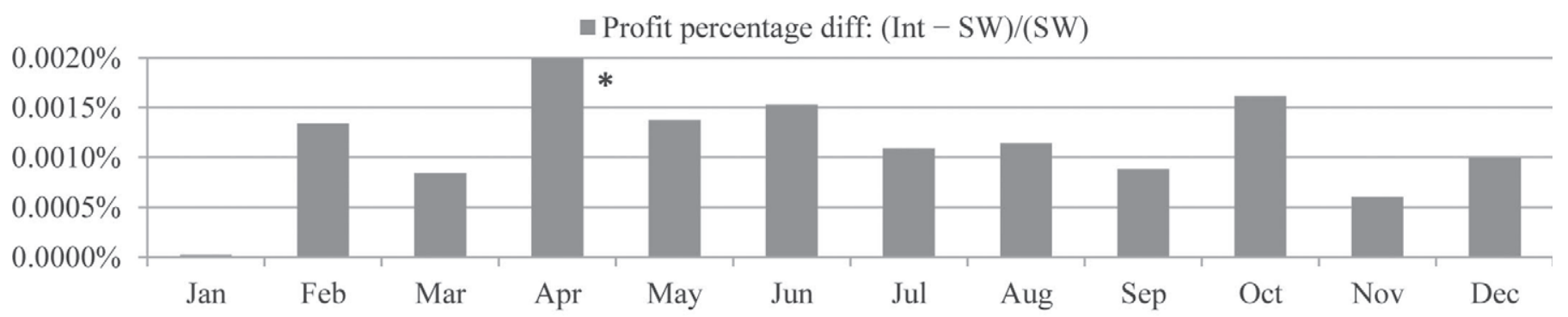

* Percentage difference in April reached 0.095\%

Figure 7. Percentage differences in profit between integral valorization (Int) and stepwise valorization (SW) cases of the base scenario.

from the production of natural cheese to IFCMP/WMP and the consequent internal demand for lactose. We refer the reader to Figure 5 to better understand the relations between shifts in production. Consequently, in the Int case, the model reallocated whey caseinate from protein-rich casein whey powder (PRCaWP) to whey protein concentrate 80 (WPC80), because the production of WPC80 allows higher production of delactosed permeate powder (DLP) that is driven by the lactose byproduct requirement. Therefore, in the Int case, we produced less PRCaWP but more WPC80 and DLP. Furthermore, lower volumes of permeate powder cheese (PPCheese) were produced. This is because the main input of the PRCheese production (i.e., permeate whey cheese) was reallocated from PPCheese to the production of DLP, again to obtain higher volumes of lactose byproduct required for the higher production of IFCMP/WMP.

Lack of increase in production of cheese and caseinate (source of casein whey) in the Int case indicates that the production of whey-based products was not profitable enough to increase the production of cheeses and caseinates. However, the limitations of the current system caused by various constraints (e.g., capacities, market) may affect this conclusion. To investigate this, we analyzed the numbers of months in which wheybased end products reached full production or market capacity. The results showed that the production of all 23 whey-based products was restricted to a certain extent, and that 17 products were limited in more than 10 mo by either or both limitations. We can therefore state that the production of whey-based end products is highly restricted. If whey-based products are profitable enough to increase the production of cheeses, the limiting capacities will not allow for the additional production of whey-based products. It is therefore possible that the effect of integral valorization would be higher if more production or market capacities were available.

The outcomes of the base scenario analysis revealed 4 main factors that might influence the level of effect of integral valorization: production capacities and 3 market-related factors (sale prices, purchase prices,

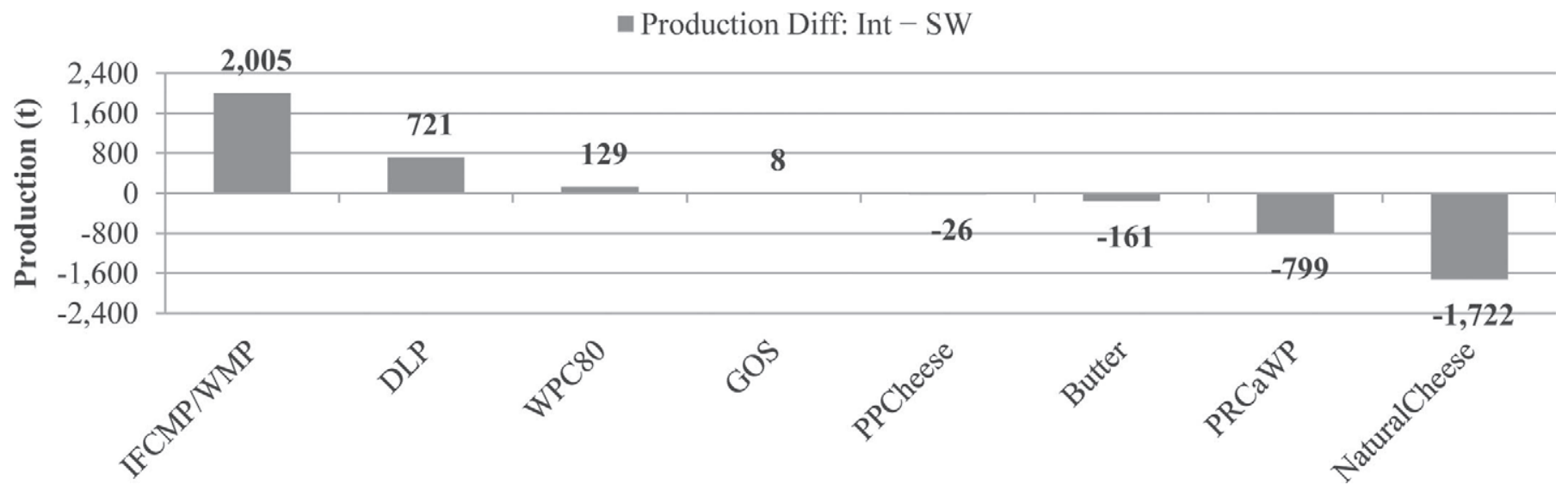

Figure 8. Yearly differences in volumes of produced end products between integral valorization (Int) and stepwise valorization (SW) according to the base scenario. IFCMP/WMP = instant full cream milk powder/whole milk powder; DLP = delactosed permeate powder; WPC80 $=$ whey protein concentrate $80 ;$ GOS $=$ galactooligosaccharides powder; PPCheese $=$ permeate powder cheese; PRCaWP $=$ protein-rich casein whey powder. 
Table 3. Scenarios defined to conduct sensitivity analysis ${ }^{1}$

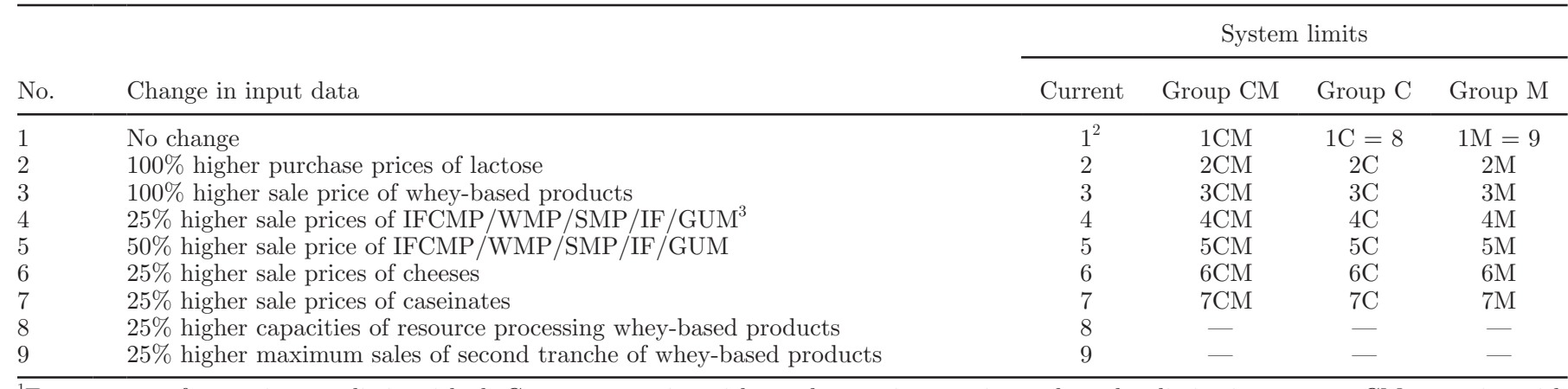

${ }^{1}$ Four groups of scenarios are distinguished: Current scenarios with no changes in capacity and market limitations; group CM scenarios with relaxed market and capacity limitations; group $\mathrm{C}$ scenarios with relaxed capacity limitations; and group $\mathrm{M}$ with relaxed market limitations.

${ }^{2}$ Scenario 1 represents base scenario against which all other scenarios are compared.

${ }^{3} \mathrm{IFCMP} / \mathrm{WMP} / \mathrm{SMP} / \mathrm{IF} / \mathrm{GUM}=$ instant full cream milk powder/whole milk powder/skim milk powder/infant formula/growing-up milk powder.

and market demand). In particular, changes in the enumerated factors of the following products may have a significant effect: whey cheese, whey casein, lactose, cheeses, caseinates, IFCMP, WMP, SMP, IF, and GUM. The first 3 products listed are byproducts produced during the valorization of nonwhey products and used for the valorization of whey products, or vice versa. The first 2 byproducts are byproducts of cheeses and caseinates obtained during the nonwhey valorization. These byproducts can be processed into whey-based products or can be sold on a market; direct sales, however, are less profitable than the postprocessing. The profitability level of whey-based products may therefore affect the production levels of cheeses and caseinates. Given the interrelations in the production of dairy products (Figure 1), changes in the production of cheeses and caseinates will affect production levels of other products. The third byproduct-lactose - can be obtained only during the valorization of whey-based products, but it can be used for the production of both whey and nonwhey products. It can also be purchased on the market, but the purchase price is much higher than the costs of internal sourcing and processing of related whey flows (production of lactose byproduct requires production of other whey-based products). The nonwhey end products that use lactose byproduct as an input are IFCMP, WMP, SMP, IF, and GUM. Depending on the cost of lactose byproduct and the sale prices of those end products, additional gain can be achieved.

\section{Second Step Analysis: Sensitivity of Results}

To confirm the conclusions drawn from the base scenario analysis and identify factors that have the greatest impact on the effect of integral valorization, additional scenarios were defined (see Table 3 ).
The first scenario represented the base scenario, against which all residual scenarios were compared. The current scenarios represent scenarios in which one input parameter was changed at a time. This allowed us to indicate the direct effect of a particular parameter on the added value of the integral valorization and to indicate the most influential parameters. In residual scenarios, limitations related only to market capacity (group $\mathbf{M}$ ), only production capacities (group $\mathbf{C}$ ), and to both market and production capacities (group $\mathbf{C M}$ ) were additionally relaxed. The scenarios of groups $\mathrm{M}$, $\mathrm{C}$, and $\mathrm{CM}$ are 2-dimensional. The first dimension represents changes in market prices of particular products and the second dimension defines the limits of the dairy system with regard to capacities ("system limits"). The profit percentage differences between Int and SW cases are presented in Table 4.

Differences in Profit. To evaluate changes in the effect of integral valorization, we first looked at percentage differences among current scenarios (see bold values in Table 4). The percentage differences indicate the percentage change between the profit difference between Int and SW cases of a given scenario and the profit difference between Int and SW cases of the base scenario. Based on the results presented in Table 4, we can state that in the given settings (i.e., production of whey-based products is highly limited by market and capacity), the increase of purchase price of lactose byproduct (scenario 2), the increase of sale price of caseinates (scenario 7), and the increase of production capacities of whey-based products (scenario 8) had no, or only a small, influence on the effect of integral valorization (percentage changes were small compared with the effect in the base scenario). The increase in sale price of whey-based products (scenario 3) and of IFCMP/WMP/SMP/GUM/IF (scenarios 4 and 5) in- 
Table 4. Profit percentage differences between the profit difference [between integral valorization (Int) and stepwise valorization (SW) cases] of a given scenario and profit difference (between Int and SW cases) of the base scenario

\begin{tabular}{|c|c|c|c|c|c|c|}
\hline \multirow[b]{2}{*}{ No. } & \multirow[b]{2}{*}{ Changes in prices } & \multicolumn{4}{|c|}{ System limits ${ }^{1}(\%)$} & \multirow{2}{*}{$\begin{array}{c}\text { Average effect } \\
\text { of a parameter } \\
(\%)\end{array}$} \\
\hline & & Current & Group CM & Group C & Group M & \\
\hline 2 & $100 \%$ higher purchase prices of lactose & 0 & 418 & 16 & 293 & 182 \\
\hline 3 & $100 \%$ higher sale price of whey-based products & 64 & 1,207 & -51 & 987 & 552 \\
\hline 4 & $25 \%$ higher sale prices of IFCMP/WMP/SMP/IF/GUM ${ }^{2}$ & 92 & 312 & -23 & 366 & 187 \\
\hline 5 & $50 \%$ higher sale price of IFCMP/WMP/SMP/IF/GUM & 84 & 285 & -67 & 176 & 119 \\
\hline
\end{tabular}

${ }^{1}$ Four groups of scenarios are distinguished: Current scenarios with no changes in capacity and market limitations; group CM scenarios with relaxed market and capacity limitations; group $\mathrm{C}$ scenarios with relaxed capacity limitations; and group $\mathrm{M}$ with relaxed market limitations. Values in bold indicate percentage differences among current scenarios in which one input parameter was changed at a time.

${ }^{2} \mathrm{IFCMP} / \mathrm{WMP} / \mathrm{SMP} / \mathrm{IF} / \mathrm{GUM}$ = instant full cream milk powder/whole milk powder/skim milk powder/infant formula/growing-up milk powder.

tensified the effect of the integral valorization. Finally, it is interesting to note that the increase in sale prices of cheeses (scenario 6) diminished the effect of integral valorization by $90 \%$, whereas the decrease in market limitations of whey-based products (scenario 9) increased the effect by almost $300 \%$. The higher effect in scenario 9 was due to the possibility of producing more DLP and Hiprotal35 products, which are the main profitable sources of lactose byproduct. Increasing demand for whey products, therefore, increased the availability of lactose byproduct in the integral valorization, and thus allowed for even higher production of IFCMP/ WMP products. The increased differences in the production of those products were observed especially in the first $4 \mathrm{mo}$, when differences between sale prices of cheese and IFCMP/WMP were the lowest. The lesser effect of scenario 6 was also due to the relation between cheese and IFCMP/WMP prices. In scenario 6 , the differences in all months between cheeses and IFCMP/ WMP were positive and, on average, they increased by $180 \%$ compared with the base scenario. Thus, in both Int and SW valorization approaches, cheeses and IFCMP/WMP were valued in the same way.

Based on the presented analysis of the profit percentage differences, we conclude that the effect of the integral valorization does not change much when selling prices or production capacities of relevant products are increased. We did, however, observe a significant increase in profit when additional demand for whey products was present. To investigate whether changes in investigated parameters would have the same effect on the effect of integral valorization, in a situation when the system was less constrained, the outcomes of scenarios of groups $\mathrm{M}, \mathrm{C}$, and $\mathrm{CM}$ were analyzed. The results are presented in Table 4 . The highest effect of the integral valorization of all scenarios was observed for scenario $3 \mathrm{CM}$; that is, $1,207 \%$ higher effect than in the base scenario. In this scenario, prices of whey products, capacity limits, and market limits were increased. This large difference, however, was mainly due to changes in market limits and prices, because in scenario $3 \mathrm{C}$, in which only capacity limits were increased, the difference in profit was 2 times smaller than in the base case $(51 \%$ lower). Furthermore, in scenarios in which sale prices of cheeses were increased, the differences in profit were consistently lower (86 to $90 \%$ lower) than the profit difference in the base scenario. The average effect of the integral valorization was highest when prices of whey products were increased $(552 \%$ higher than the effect in the base scenario), and lowest when prices of cheeses were increased ( $88 \%$ lower; see last column of Table 4).

Following the presented analysis, the effect of the integral valorization will increase if the prices of whey products also increase. Given developments in the value of whey in recent years (see Figure 2 and Figure 9), this increase is very possible. As one can see from Figure 9, the percentage differences in prices of 2 representative whey end products (WPC and whey powder) easily reached $50 \%$ in the last $10 \mathrm{yr}$. In 2004, 2009-2010, and 2012 , the percentage differences reached $100 \%$, and in 2007 reached $170 \%$.

Furthermore, if in addition to whey prices, demand for whey products increases, gains from the integral valorization could be even higher. It should be kept in mind that the increase in cheese prices will decrease the effect of integral valorization.

Shifts in Production Planning. To investigate whether the integral valorization may lead to different decisions regarding the production of nonwhey products, differences in production and total allocation of raw milk between Int and SW cases were analyzed (see Figure 10 with yearly differences).

In most scenarios, larger shifts from natural cheese production to IFCMP/WMP were observed in the Int 

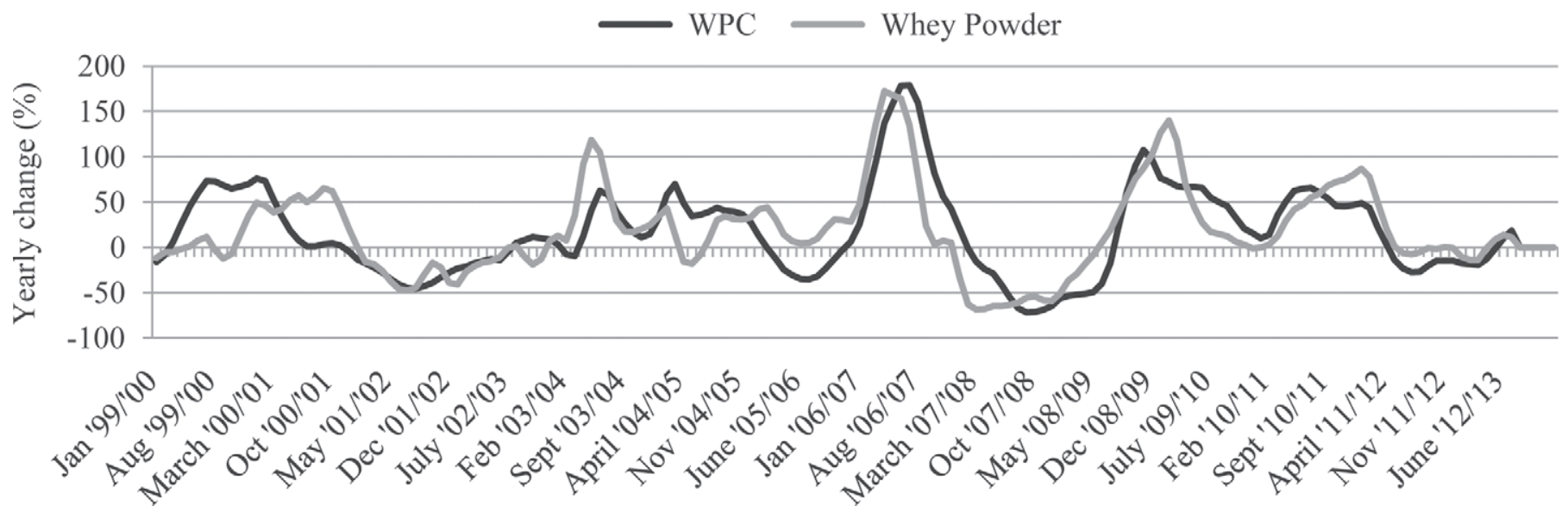

Figure 9. Yearly percentage changes in sale prices calculated based on monthly data; for example, Jan '10/'11 indicates the following (Price_Jan_2011 - Price_Jan_2010)/Price_Jan2010. WPC = whey protein concentrate.

cases than in the SW cases. The differences in shifts did not occur in scenarios with higher sale prices of cheeses $(6,6 \mathrm{CM}, 6 \mathrm{C}$, and $6 \mathrm{M})$ or those with higher sale prices of IFCMP/WMP and relaxed capacity constraints $(4 \mathrm{C}$ and $5 \mathrm{C}$ ). This is because the differences between prices of cheeses and IFCMP/WMP increased in those scenarios, and both Int and SW valorizations valued both product groups similarly. Furthermore, in scenarios $5 \mathrm{CM}, 5 \mathrm{C}$, and $5 \mathrm{M}$, additional differences in the production of evaporated milk (EVAP) were observed. These are scenarios with 50\% higher sale prices of IFCMP/ WMP. In all months, the additional milk required for the production of IFCMP/WMP was withdrawn from cheese production. In February, cheese was produced at its minimum required volume (that necessary to fulfill contracted sales) and thus additional raw milk necessary for the profitable production of IFCMP/WMP was, in that month, withdrawn from EVAP. This is a product that delivers second lowest return on $1 \mathrm{t}$ of raw milk used in the end production (the product with the low-

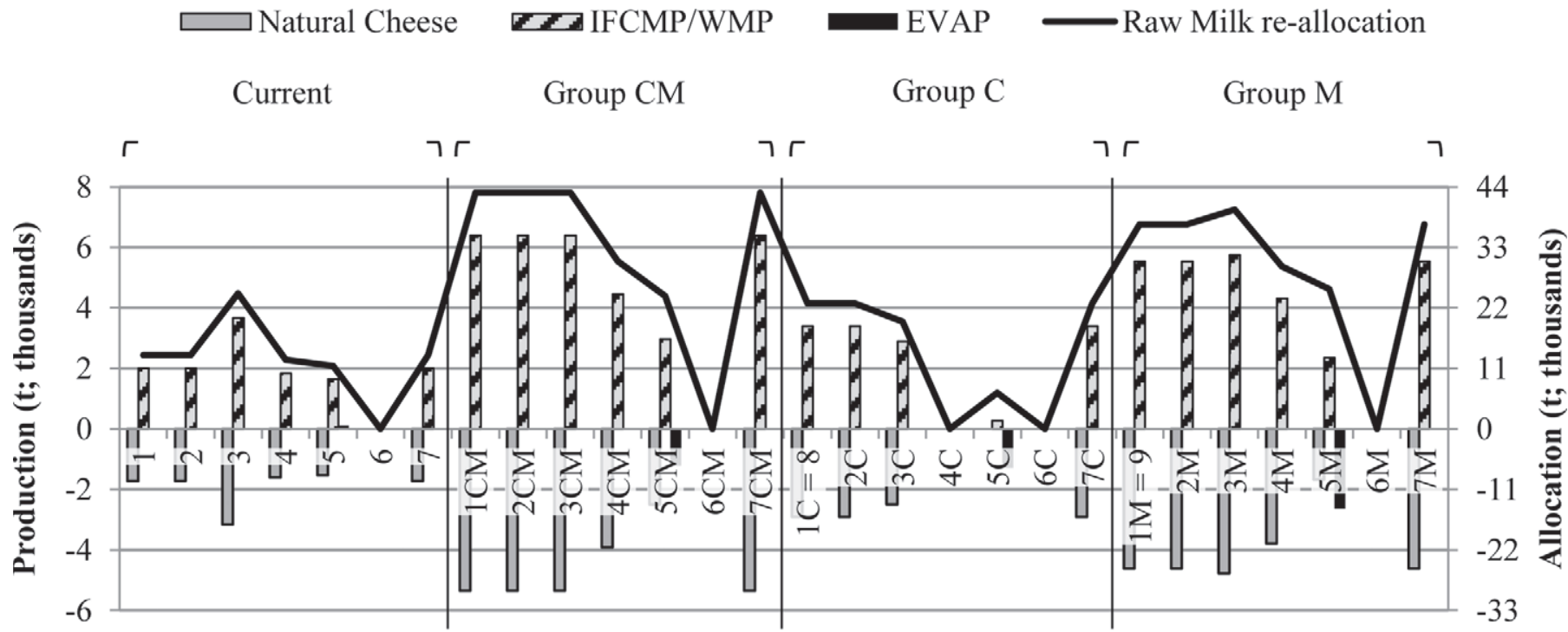

Scenario

Figure 10. Main yearly differences in production of end products (left axis; thousand tonnes) and allocation of raw milk (right axis; thousand tonnes) between integral valorization (Int) and stepwise valorization (SW) cases. Current scenarios = no changes in capacity and market limitations; group CM scenarios = relaxed market and capacity limitations; group $\mathrm{C}$ scenarios = relaxed capacity limitations; and group $\mathrm{M}$ $=$ relaxed market limitations. $\mathrm{IFCMP} / \mathrm{WMP}=$ instant full cream milk powder/whole milk powder; EVAP = evaporated milk. Definitions of scenarios are given in Table 3. 
est return is cheese). Therefore, the positive differences in the production volumes of IFCMP/WMP between Int and SW cases lead to negative differences in production volumes of EVAP. Furthermore, the differences presented in Figure 10 also lead to differences in butter production, because lower production of cheese leads to lower production of cream, which is the main input for the production of butter.

An important conclusion from the analysis of the outcome depicted in Figure 10 is that incorporation of information on the value of processing whey products in the valorization of main dairy products negatively affects the production of cheeses. This means that, currently, whey products are not profitable enough to drive the production of cheese and caseinate products.

Based on this study, we conclude that under current capacity and market demand limitations, the effect of integral valorization in the dairy case is small. Therefore, the valorization of main products and whey byproducts can be conducted separately without any larger losses. Because of low gains and high integration costs, it is currently recommended to conduct the valorization processes separately, as is the current practice. A large potential of integrating valorization processes is available, however. The possibility of extending markets and sale prices of whey-based products should be investigated. Finally, dairy producers should closely monitor the relation of cheeses and milk powders prices. In situations where prices of milk powders considerably increase, the gain from integrating valorization processes becomes much higher.

Our conclusions on the effect of whey valorization and integral valorization are based on the dairy industry. Nonetheless, the methodology presented in this work can easily be used to verify whether these conclusions hold for other industries. In this study, we evaluated the effect of price, demand, and capacity on integral valorization. The effect of new whey production recipes should also be investigated. An outcome of such a study could indicate unexplored benefits of the integral valorization.

\section{CONCLUSIONS}

The aim of this study was to analyze the added value of valorizing byproducts from an economic perspective; that is, the producers' point of view. We used the dairy industry as a case study, and focused on the byproduct of cheese production; that is, whey. This byproduct was chosen because of its important economic and environmental aspects. With the use of multiple scenarios implemented in the IDVM, we have shown the following. Explicit valorization of whey products resulted in considerable additional profit. The effect of integral valorization in the current settings of the dairy system was small (this finding is contrary to the expectations of professionals). The effect of integral valorization can change significantly in case changes in the following key factors occur: demand for or prices of whey-based products increase, sale prices of cheeses increase, or production capacity of whey-based products is extended. We expect these key factors (i.e., capacities, prices and demand of products linking processing of main products with byproducts processing) to also drive the valorization of byproducts in other industries. Finally, we investigated whether the inclusion of whey valorization into the current milk valorization process would affect decisions on production volumes of nonwhey end products. We showed that a consistently larger shift from the production of natural cheese to the production of IFCMP/WMP occurred in Int valorization compared with SW valorization. Those shifts were caused by small differences in margin of those products between Int and SW cases. Although the relation between prices was known in practice, our finding of the effect upon the integral valorization was unknown.

\section{REFERENCES}

Banaszewska, A., F. Cruijssen, J. G. A. J. van der Vorst, G. D. H. Claassen, and J. L. Kampman. 2013. A comprehensive dairy valorization model. J. Dairy Sci. 96:761-779.

Chedea, V. S., P. Kefalas, and C. Socaciu. 2010. Patterns of carotenoid pigments extracted from two orange peel wastes (Valencia and Navel var.). J. Food Biochem. 34:101-110.

Cuartas-Uribe, B., M. I. Alcaina-Miranda, E. Soriano-Costa, J. A. Mendoza-Roca, M. I. Iborra-Clar, and J. Lora-García. 2009. A study of the separation of lactose from whey ultrafiltration permeate using nanofiltration. Desalination 241:244-255.

Darine, S., V. Christophe, and D. Gholamreza. 2010. Production and functional properties of beef lung protein concentrates. Meat Sci. $84: 315-322$.

FAO. 2009. Agribusiness handbook: Milk/dairy products. Food and Agriculture Organization of the United Nations (FAO), Rome, Italy.

FAPRI (Food and Agricultural Policy Research Institute). 2012. International Dairy Model. Accessed Mar. 20, 2012. http://www.fapri. iastate.edu/models/dairy.aspx.

Farhat, A., A.-S. Fabiano-Tixier, M. E. Maataoui, J.-F. Maingonnat, M. Romdhane, and F. Chemat. 2011. Microwave steam diffusion for extraction of essential oil from orange peel: Kinetic data, extract's global yield and mechanism. Food Chem. 125:255-261.

Galanakis, C. M. 2011. Olive fruit dietary fiber: Components, recovery and applications. Trends Food Sci. Technol. 22:175-184.

Galanakis, C. M. 2012. Recovery of high added-value components from food wastes: Conventional, emerging technologies and commercialized applications. Trends Food Sci. Technol. 26:68-87.

Gehring, C. K., J. C. Gigliotti, J. S. Moritz, J. C. Tou, and J. Jaczynski. 2011. Functional and nutritional characteristics of proteins and lipids recovered by isoelectric processing of fish byproducts and low-value fish: A review. Food Chem. 124:422-431.

González-Martínez, C., M. Becerra, M. Cháfer, A. Albors, J. M. Carot, and A. Chiralt. 2002. Influence of substituting milk powder for whey powder on yoghurt quality. Trends Food Sci. Technol. 13:334-340.

Gonzalez-Siso, M. 1996. The biotechnological utilization of cheese whey: A review. Bioresour. Technol. 57:1-11. 
Guimarães, P. M. R., J. A. Teixeira, and L. Domingues. 2010. Fermentation of lactose to bio-ethanol by yeasts as part of integrated solutions for the valorisation of cheese whey. Biotechnol. Adv. $28: 375-384$.

Gustavsson, J., C. Cederberg, U. Sonesson, R. Van Otterdijk, and A. Meybeck. 2011. Global food losses and food waste. Food and Agriculture Organization of the United Nations, Dusseldorf, Germany.

Hollmann, J., and M. G. Lindhauer. 2005. Pilot-scale isolation of glucuronoarabinoxylans from wheat bran. Carbohydr. Polym. $59: 225-230$.

Koutinas, A. A., H. Papapostolou, D. Dimitrellou, N. Kopsahelis, E. Katechaki, A. Bekatorou, and L. A. Bosnea. 2009. Whey valorisation: A complete and novel technology development for dairy industry starter culture production. Bioresour. Technol. 100:37343739 .

Marwaha, S., and J. Kennedy. 1988. Whey-Pollution problem and potential utilization. Int. J. Food Sci. Technol. 23:323-336.

Mollea, C., L. Marmo, and F. Bosco. 2013. Valorisation of cheese whey, a byproduct from the dairy industry. Pages 549-588 in Food Industry. InTech, Rijeka, Croatia.

Panesar, P. S., J. F. Kennedy, D. N. Gandhi, and K. Bunko. 2007. Bioutilisation of whey for lactic acid production. Food Chem. 105:1-14
Parfitt, J., M. Barthel, and S. MacNaughton. 2010. Food waste within food supply chains: quantification and potential for change to 2050. Philos. Trans. R. Soc. Lond. B Biol. Sci. 365:3065-3081.

Patel, S. R., and Z. V. P. Murthy. 2011. Waste valorization: Recovery of lactose from partially deproteinated whey by using acetone as anti-solvent. Dairy Sci. Technol. 91:53-63.

Prazeres, A. R., F. Carvalho, and J. Rivas. 2012. Cheese whey management: A review. J. Environ. Manage. 110:48-68.

Russ, W., and R. Meyer-Pittroff. 2004. Utilizing waste products from the food production and processing industries. Crit. Rev. Food Sci. Nutr. 44:57-62.

Smithers, G. W. 2008. Whey and whey proteins-From 'gutter-togold'. Int. Dairy J. 18:695-704.

Sun, R. C., and J. Tomkinson. 2002. Characterization of hemicelluloses obtained by classical and ultrasonically assisted extractions from wheat straw. Carbohydr. Polym. 50:263-271.

Yang, H., F. Yan, D. Wu, M. Huo, J. Li, Y. Cao, and Y. Jiang. 2010. Recovery of phytosterols from waste residue of soybean oil deodorizer distillate. Bioresour. Technol. 101:1471-1476. 